\title{
Association of Superoxide Dismutase, Glutathione Peroxidase, Catalse, and Xanthine Oxidase with Incidence of Bladder Cancer
}

\author{
Shatha Rouf Moustafa \\ Clinical Analysis Department, College of Pharmacy, Hawler Medical University, Havalan City, Erbil, Iraq
}

\section{Email address:}

shatha003@yahoo.com

To cite this article:

Shatha Rouf Moustafa. Association of Superoxide Dismutase, Glutathione Peroxidase, Catalse, and Xanthine Oxidase with Incidence of Bladder Cancer. Cancer Research Journal. Vol. 3, No. 2, 2015, pp. 17-27. doi: 10.11648/j.crj.20150302.11

\begin{abstract}
Background: Emerging evidence indicates a potential role of anti-oxidant enzymes in the prevention of bladder cancer. Aims: This study assessed the correlation between the anti-oxidative enzymes with bladder cancer incidence. The present study was aimed to estimate the levels of superoxide dismutase, glutathione peroxidase, catalase and xanthine oxidase in patients to perform a comprehensive analysis of bladder cancer antioxidant capacity. These parameters were correlated with other confounding factors age, gender, smoking, grade, stage, and tumor size and find out the correlation between all studied parameters to clarify the potential link between antioxidant enzymes expression and disease progression or metastatic dissemination. Method: This case control study was done at College of Pharmacy/Hawler Medical University in period between 15/4/2013 and 15/ 4/2014 on 50 newly diagnosed patients with bladder cancer of both genders (48 men and 2 women) with a mean age $65.12 \pm 10.23$ years, and an equal number of matched gender-age ( 47 men and 3 women ) apparently healthy adults were also enrolled in this study with a mean age $62 \pm 9.593$ years. The antioxidant enzymes were measured using high pressure liquid chromatography. Data was analyzed using Statistical Package for Social Scientists (SPSS) version 18.0. Results: There were a significant reduction in the serum superoxide dismutase, glutathione peroxidase, catalase levels and a significant elevation in the serum xanthine oxidase level, there were no significant age differences between all age categories regarding all studied parameters except, xanthine oxidase levels, there were a significant differences between two age categories 60-69 and $70, p=0.023$, there were significant differences between two age categories $<60$ and $60-69$ regarding tumor size $p=0.042$, there were no significant effect of smoking, grade and stage on the serum studied parameters levels. There were no signification correlation coefficient between all studied parameters. Conclusions: These findings supported the concept that significant reduction in the serum super oxide dismutase, glutathione peroxidase, and catalase levels accompanied with significant elevation in the serum xanthine oxidase level might be a pathogenic and prognostic factors in bladder cancer. This investigation therefore focused on the measurement of variables indicative of imbalances in oxidative and anti-oxidative status. Variations in antioxidant enzyme activities might be a potentially important finding as an additional diagnostic biochemical tool for BC .These findings suggest possible use of antioxidant supplementation as prophylactic agents for prevention and treatment of bladder cancer.
\end{abstract}

Keywords: Bladder Cancer, Superoxide Dismutase, Glutathione Peroxcidase, Catalase, Xanthine Oxidase

\section{Introduction}

Bladder cancer is the commonest type of malignant tumors which is a major healthy problem world wild. Clinical characteristic of bladder cancer is still insufficient using specific standard prognostic parameters.

Bladder cancer (BC) is the 7th most predominant cancer in men and the 17th most predominant in women in the world. The prevalence of $\mathrm{BC}$ varies considerably among countries, with the highest incidence rates seen in Western countries and the lowest rates in Asian countries [1]. While, in the Unite State, BC ranks the fourth most predominant cancer in men and ninth in women. More than $90 \%$ of BCs are transitional cell carcinomas. Bladder cancer, in Iraq is the third most predominant malignancy tumor in both men and women, it's the second most predominant in men and ninth in 
women [2]. According to the latest WHO data reported in April 2011 BC in Iraq reached 977 or $0.52 \%$ of total deaths. The adjusted death rates is 7.55 per 100,000 of population ranks Iraq three in the world. In Iraq, BC represents the commonest malignancy in all diagnosed cancer cases according to the registry of Iraqi Cancer Registry [2].

The disturbance of the oxidant /antioxidant balance, resulting from elevated free radical generation, antioxidant enzyme inactivation, and excessive antioxidant consumption, is the causative effect in oxidative harmful[3]. Reactive oxygen species (ROS) can damage variant cellular macromolecules, including carbohydrate, lipid DNA and proteins. The primary target of the oxidation differs depending on the type of cell and location of oxidative stress (OS) and its severity, and availability of metal ions [4]. There is some evidence suggesting that $\mathrm{OS}$ and $\mathrm{BC}$ are closely related [5]. Recently, there has been focused interest in research of the role of free radicals (FRs) in carcinogenesis and the role of antioxidant materials in the prevention, treatment, and alleviation of therapy related side effects of cancer [6]. Inherent OS may affect several functions in cancer cells and tissues, such as invasion, cell proliferation, metastasis, promotion of mutations, genetic instability and alterations in cellular sensitivity to anticancer agents [7]. In response to oxidative damage, cells have developed an antioxidant defense mechanism to maintain cellular redox homeostasis and to protect cells from harmful effect [8].

Several proteins are directly involved in ROS removal. These include superoxide dismutase (SOD), glutathione peroxidase (GPX), catalase (CAT), among these, CAT, SOD, and GPX directly neutralize ROS. Catalase and GPX convert hydrogen peroxide to water. However, excess ROS can overwhelm the capacity of the antioxidant system, the total antioxidant activity in the cells was not adequate to neutralize the damaged effects of FRs [9].

Oxidative stress is a condition of imbalance between ROS formation and cellular antioxidant capacity due to enhanced ROS generation and/or impaired of the antioxidant functions. Mutagenesis is stimulated in response to a moderate level of OS. Weak oxidative conditions play a role in tumor promotion, whereas high levels of FRs are involved in apoptosis [10]. In order to prevent harmful effect of accumulation of damaged DNA, protein, lipids and subsequent initiation of carcinogenesis. Cell has a complex and very effective antioxidant defense system that permit an immediate response to OS. Various enzymatic antioxidants like SOD, CAT, GPX, and XO act together to render ROS/reactive nitrogen species (RNS).

Epidemiological studies reveal that low levels of antioxidants are associated with an increased risk of cancer. Antioxidant depletion in the circulation may be due to the scavenging of lipid peroxides as well as sequestration by tumor cells [11]. Oxidative stress stimulate a cellular redox imbalance that has been present in various cancer cells as compared with normal cells, the redox imbalance thus may be related to oncogenic stimulation [6].

There is considerable evidence to support the role of OS in the development of many diseases such as cancer. Reactive oxygen species directly promote the oxidative damage of genes. As a consequence, the presence of ROS can lead to deregulation of transcription, genomic instability, induction of mitogenic, signal transduction pathways and replication errors, all of which may increase the risk of cancer development [12]. Decreased levels of SOD, CAT and GPX are also reported in transformed cell lines [13]. Eventually, the effect of anti-oxidant enzymes affect the biochemical, physiological, and/or cellular processes that inactivate FRs or that stop free radical-initiated chemical reactions.

\subsection{Superoxide Dismutase (E.C. 1.15.1.1)}

It catalyses the dismutation of superoxide anion $\left(\mathrm{O}_{2}{ }^{\circ,-}\right)$ to hydrogen peroxide $\left(\mathrm{H}_{2} \mathrm{O}_{2}\right)$, a major cellular scavenger of superoxide anion radicals, have increased rates of liver cancer development later in life [14]. The $\mathrm{H}_{2} \mathrm{O}_{2}$ generated by SOD enzymes in mitochondria and cytosol is probably largely removed by thioredoxin-dependent peroxidase enzymes, and GPXs also contributed [15].

\subsection{Glutathione Peroxidase (E.C. 1.11.1.9)}

Glutathione peroxidase (selenium-containing enzymes) is the general name of an enzyme family with peroxidase activity whose main function is to protect the organism from oxidative damage. It catalyzes the conversion of $\mathrm{H}_{2} \mathrm{O}_{2}$ and hydroperoxides producing from unsaturated fatty acids peroxidation at the expense of reduced glutathione are considered to be the primary antioxidant enzymes, as they are associated in direct removal of active oxygen. The biochemical role of GPX is to decrease lipid hydroperoxides to their corresponding alcohols and to reduce free $\mathrm{H}_{2} \mathrm{O}_{2}$ to water. This enzyme has a role in disease, genetic polymorphisms in GPX enzymes and their varied expressions and functions are contributed with oxidative DNA damage and as a result of the individual's risk of cancer susceptibility [16].

\subsection{Catalase (EC 1.11.1.6)}

The major function of this enzyme contributes controlling $\mathrm{H}_{2} \mathrm{O}_{2}$ concentrations in human cells, converting $\mathrm{H}_{2} \mathrm{O}_{2}$ into $\mathrm{H}_{2} \mathrm{O}$ and $\mathrm{O}_{2}$ [17]. One catalase molecule can convert millions of molecules of $\mathrm{H}_{2} \mathrm{O}_{2}$ into $\mathrm{H}_{2} \mathrm{O}$ and $\mathrm{O}_{2}$ each second [18]. Catalase is present in a cell organelle called the peroxisome. It has one of the highest turnover rates for all enzymes. It is a predominant enzyme found in nearly all living organisms exposed to oxygen. Catalase is highly located in some tissues and protected cells against the excessive formation of ROS. Catalase prevents the accumulation of $\mathrm{H}_{2} \mathrm{O}_{2}$ that are formed during oxygen transport process. According to recent studies, low levels of CAT may play a role in the developing many diseases. The variation in the concentration of catalase are associated with oxidative DNA damage and subsequently the individual's risk of cancer susceptibility [16]. Accumulative evidence has shown that redox balance is destroyed in cancer tissue compared with normal tissue, which may be associated 
to oncogenic stimulation.

Altered levels of antioxidant enzymes SOD, CAT, GPX as changes in the related signal pathways are evident in many human cancers [19].

\subsection{Xanthine Oxidase (EC 1.17.3.2)}

It is defined as an enzyme which is playing a part in purine metabolism. It catalyzes the conversion of hypoxanthine to xanthine and xanthine to uric acid, the last reaction in the purine catabolism, with byproduct of toxic superoxide radical In this regard, it is a key enzyme between purine and FR metabolism. It was reported that $\mathrm{XO}$ is an endogenous source of ROS and RNS that can induce OS and inflect tissue injury [20]. There is growing evidence that superoxide radicals generated by $\mathrm{XO}$ are primarily responsible for the cellular deterioration associated with several conditions [21].

On the light of these above information, it was aimed to evaluate the levels of, SOD, GPX, CAT, and XO in patients with $\mathrm{BC}$ and find out their association with other confounding factors age, gender, smoking, grade, stage, and tumor size and their possible relation with incidence, progression, and development, finally find out the correlation between all studied parameters, in order to perform a comprehensive analysis of $\mathrm{BC}$ antioxidant capacity.

\section{Patients and Methods}

This study was conducted to assess the prognostic impact of altered expressions of antioxidant enzymes in patients with BC. This study was performed at Hawler Medical University, College of Pharmacy in period between 15/4/2013 and 15/ 4/2014 on 50 newly diagnosed patients with BC of both genders (48 men and 2 women) with a mean age 65.12 \pm 10.23 years at the diagnosis, and an equal number of matched gender-age apparently healthy adults were also enrolled in this study as a control group for comparing purposes. This group included 47 men and 3 women with a mean age $62 \pm 9.593$ years. The control group were confirmed to be normal by biochemical and hematological examinations All patients have these general criteria, newly diagnosed, no deep X- ray therapy, no chemotherapy, and no hormonal therapy with histologic and cytologic confirmation of BC. All patients had histopathological reports that proved their diagnoses.

All patients were subjected to a detailed history investigation and underwent thorough clinical examination, abdominal and pelvic ultrasonography, chest X-ray, computed tomography urine cytology, and histopathological diagnosis of urinary bladder biopsies obtained by cystoscopy. All patients who enrolled in the present study exhibited no clinically malignant disease other than $\mathrm{BC}$. None of the patients had any other significant diseases. All diagnosed patients were confirmed by at least one relevant biopsy in addition to other relevant findings, including history, physical examination, laboratory data, and clinical course. All procedures were in accordance with established ethical standards.
Patients completed a questionnaire paper related to family history, past medical history, and medication history. For each patient, a case sheet that included the following information was prepared: age, gender, chief complain, investigations (biochemical, hematological, histopathological, cytological, and urine cytology. All clinicopathological data of the patients, including tumor type, grade, and stage, tumor size were collected from their pathological reports and clinical files. Oral consent was obtained from all participants before their participation in this study.

\subsection{Methods}

\section{The Protocol of the Study}

I- Tissue biopsies were sent to the histopathological laboratory to diagnose the bladder cancer type, grade,stage, and tumor size.

II- The fasting blood samples $(10 \mathrm{ml})$ aspirated from the vein of the participants left 30 minutes for coagulation, centrifuged and separated the sera and kept frozen till the day of analysis .

\subsection{Biochemical Determinations}

The studied parameters were measured by high pressure liquid chromatography (HPLC).

\subsection{Statistical Studies}

Data analyzed using (SPSS vi.18). The results expressed as mean \pm SD. t-test applied to compare between two means. Post Hoc test used to show the significant difference between two of three variables. Multiple regression used to show the association between each of the biomarker (as a dependent variables) and several independent variables. $\mathrm{P}$ value of $\leq$ 0.05 considered statistical significance.

\section{Results}

The present study addressed, the role of SOD, GPX, CAT, and $\mathrm{XO}$ altered expressions (at the protein levels) in Erbil patients with BC illustrated the clinical significance of these aberrations either singular or in combination. Aberrations involving these parameters were also correlated with other confounding factors age, gender, smoking, grade, stage and tumor size and finally find out the correlation between all studied parameters.

\subsection{Baseline Characteristics}

The studied group comprised, $96 \%$ of patients were men, and about $4 \%$ were women. The mean age at diagnosis was $65 \pm 10.23$ years. The characteristics of the patients group was shown in (Table 1), $40 \%$ of the patients group were smokers and $60 \%$ were non - smokers, while $56 \%$ of the patients with in stage $\mathrm{I}\left(\mathrm{T}_{1}\right)$ and $44 \%$ of the patients with in stage II $\left(\mathrm{T}_{2}\right)$, in addition, $26 \%, 40 \%$, and $34 \%$ of patients had grade I, II, III respectively. Moreover, the tumor size was $350.52 \pm 374.44$. 
Table 1. The characteristics of the studied participants

\begin{tabular}{lll}
\hline & Control & Patient \\
\hline Number & $\mathbf{5 0}$ & $\mathbf{5 0}$ \\
\hline Smoking \% & 44 & 40 \\
& $\mathrm{n}=22$ & $\mathrm{n}=20$ \\
Non-Smoking\% & 56 & 60 \\
& $\mathrm{n}=28$ & $\mathrm{n}=30$ \\
Males \% & 94 & 96 \\
& $\mathrm{n}=47$ & $(\mathrm{n}=48)$ \\
Females\% & 6 & 4 \\
& $\mathrm{n}=3$ & $(\mathrm{n}=2)$ \\
Stage I \% & & 56 \\
& & $(\mathrm{n}=28)$ \\
Stage II\% & & 44 \\
& & $(\mathrm{n}=22)$ \\
Grade 1\% & & 26 \\
& & $(\mathrm{n}=13)$ \\
Grade 2\% & & 40 \\
Grade 3\% & & $(\mathrm{n}=20)$ \\
Tumor size & & 34 \\
Age (Mean) & & $(\mathrm{n}=17)$ \\
\pm SD & & $350.52 \pm 374.44$ \\
& & 65.12 \\
& & 10.23 \\
\hline
\end{tabular}

\subsection{Effect of Bladder Cancer on the Serum Levels of Studied Parameters}

Laboratory studies have shown that there were a significant reduction in the serum levels of SOD, CAT, and GPX levels as compared with the control group which was accompanied by a significant elevation in the serum level of XO (Table 2), these findings were accordant with the hypothesis of the study. As shown in (Table 2), the serum level of SOD in patient and control groups were $149.140 \pm$ $29.65,201 \pm 31.4$ respectively, while, the serum level of GPX in patient and control groups were $131.0076 \pm 14.46$,
$170 \pm 28$ respectively and the serum level of CAT in patient and control were $10.4430 \pm 2.47,20 \pm 4.3$ respectively, in addition, the serum level of $\mathrm{XO}$ in patient and control were $2.245 \pm 0.832,0.8 \pm 0.5$ respectively.

\subsection{Age-Effect}

The characteristics of the participants were presented in (Table 1), the mean age of patients at diagnosis were $65 \pm$ 10.23 , while the mean age of the control group was $62 \pm$ 9.593. There were no significant age differences between all age categories regarding all studied parameters except, XO serum levels, there were a significant differences between two age categories $60-69$ and $70, p=0.023$. Moreover, there were significant differences between two age categories $<60$ and 60-69 regarding tumor size $\mathrm{p}=0.042$ (Table 3). In addition, the correlation between all studied parameters, with age factor was shown in (Table 7), there was negative weak non significant correlation between age and SOD,CAT and tumor size $\mathrm{r}=-0.04, \mathrm{p}=0.776 ; \mathrm{r}=-0.08, \mathrm{p}=0.957 ; \mathrm{r}=-0.035$, $\mathrm{p}=0.809$ respectively, while there were a positive weak non significant correlation between age with GPX, XO r=0.019, $\mathrm{p}=0.894 ; \mathrm{r}=0.132, \mathrm{p}=0.360$ respectively.

Table 2. The effect of the bladder cancer on the serum levels of the studied parameters

\begin{tabular}{llll}
\hline & Patients & Control & P-value \\
\hline SOD u/ml & $149.140 \pm 29.65$ & $201 \pm 31.4$ & $<0.001$ \\
GPX u/L & $131.0076 \pm 14.46$ & $170 \pm 28$ & $<0.001$ \\
CAT u/L & $10.4430 \pm 2.47984$ & $20 \pm 4.3$ & $<0.001$ \\
XO u/L & $2.245 \pm 0.832$ & $0.8 \pm 0.5$ & $<0.001$ \\
Number & 50 & 50 & \\
\hline
\end{tabular}

Table 3. Comparison between different age categories regarding the serum levels of the studied parameters

\begin{tabular}{|c|c|c|c|c|c|c|c|}
\hline \multicolumn{8}{|l|}{ Post Hoc Tests } \\
\hline \multirow{2}{*}{ Dependent Variable } & \multirow{2}{*}{ (I) Age_groups } & \multirow{2}{*}{ (J) Age_groups } & \multirow{2}{*}{ Mean Difference (I-J) } & \multirow{2}{*}{ Std. Error } & \multirow{2}{*}{ Sig. } & \multicolumn{2}{|c|}{ 95\% Confidence Interval } \\
\hline & & & & & & Lower Bound & Upper Bound \\
\hline \multirow{6}{*}{$\mathrm{SOD} \mathrm{u} / \mathrm{ml}$} & \multirow{2}{*}{$<60$} & $60-69$ & 2.1209 & 11.442 & 0.854 & -20.898 & 25.140 \\
\hline & & $70+$ & -2.5165 & 12.038 & 0.835 & -26.735 & 21.702 \\
\hline & \multirow{2}{*}{$60-69$} & $<60$ & -2.1209 & 11.442 & 0.854 & -25.140 & 20.898 \\
\hline & & $70+$ & -4.6373 & 9.661 & 0.633 & -24.074 & 14.800 \\
\hline & \multirow{2}{*}{$70+$} & $<60$ & 2.5165 & 12.038 & 0.835 & -21.702 & 26.735 \\
\hline & & $60-69$ & 4.6373 & 9.661 & 0.633 & -14.800 & 24.074 \\
\hline \multirow{6}{*}{ GPX u/l } & \multirow{2}{*}{$<60$} & $60-69$ & -8.07148 & 5.4621 & 0.146 & -19.0600 & 2.9170 \\
\hline & & $70+$ & -7.24329 & 5.74687 & 0.214 & -18.8045 & 4.3179 \\
\hline & \multirow{2}{*}{$60-69$} & $<60$ & 8.07148 & 5.4621 & 0.146 & -2.9170 & 19.0600 \\
\hline & & $70+$ & 0.82818 & 4.6122 & 0.858 & -8.4505 & 10.1069 \\
\hline & \multirow{2}{*}{$70+$} & $<60$ & 7.24329 & 5.7468 & 0.214 & -4.3179 & 18.8045 \\
\hline & & $60-69$ & -0.82818 & 4.6122 & 0.858 & -10.1069 & 8.4505 \\
\hline \multirow{6}{*}{$\mathrm{XO}$ u/l } & \multirow{2}{*}{$<60$} & $60-69$ & 0.16548 & .30404 & 0.589 & -.4462 & .7771 \\
\hline & & $70+$ & -0.43859 & .31989 & 0.177 & -1.0821 & .2049 \\
\hline & \multirow{2}{*}{$60-69$} & $<60$ & -0.16548 & .30404 & 0.589 & -.7771 & .4462 \\
\hline & & $70+$ & $-0.60407^{*}$ & .25673 & 0.023 & -1.1205 & -.0876 \\
\hline & \multirow{2}{*}{$70+$} & $<60$ & 0.43859 & .31989 & 0.177 & -.2049 & 1.0821 \\
\hline & & $60-69$ & $0.60407^{*}$ & .25673 & 0.023 & .0876 & 1.1205 \\
\hline \multirow{5}{*}{ CATu/1 } & \multirow{2}{*}{$<60$} & $60-69$ & 0.25178 & .95648 & 0.794 & -1.6724 & 2.1760 \\
\hline & & $70+$ & -0.15241 & 1.00633 & 0.880 & -2.1769 & 1.8721 \\
\hline & \multirow{2}{*}{$60-69$} & $<60$ & -0.25178 & 0.95648 & 0.794 & -2.1760 & 1.6724 \\
\hline & & $70+$ & -0.40419 & 0.80765 & 0.619 & -2.0290 & 1.2206 \\
\hline & $70+$ & $<60$ & 0.15241 & 1.00633 & 0.880 & -1.8721 & 2.1769 \\
\hline
\end{tabular}




\begin{tabular}{|c|c|c|c|c|c|c|c|}
\hline \multicolumn{8}{|l|}{ Post Hoc Tests } \\
\hline \multirow{2}{*}{ Dependent Variable } & \multirow{2}{*}{ (I) Age_groups } & \multirow{2}{*}{ (J) Age_groups } & \multirow{2}{*}{ Mean Difference (I-J) } & \multirow{2}{*}{ Std. Error } & \multirow{2}{*}{ Sig. } & \multicolumn{2}{|c|}{ 95\% Confidence Interval } \\
\hline & & & & & & Lower Bound & Upper Bound \\
\hline \multirow{7}{*}{ Tumor_size } & \multirow{3}{*}{$<60$} & $60-69$ & 0.40419 & 0.80765 & 0.619 & -1.2206 & 2.0290 \\
\hline & & $60-69$ & $286.11304^{*}$ & 136.97326 & 0.042 & 10.5584 & 561.6677 \\
\hline & & $70+$ & 174.61176 & 144.11201 & 0.232 & -115.3042 & 464.5277 \\
\hline & \multirow{2}{*}{$60-69$} & $<60$ & $-286.11304^{*}$ & 136.97326 & 0.042 & -561.6677 & -10.5584 \\
\hline & & $70+$ & -111.50128 & 115.66031 & 0.340 & -344.1798 & 121.1773 \\
\hline & \multirow{2}{*}{$70+$} & $<60$ & -174.61176 & 144.11201 & 0.232 & -464.5277 & 115.3042 \\
\hline & & $60-69$ & 111.50128 & 115.66031 & 0.340 & -121.1773 & 344.1798 \\
\hline
\end{tabular}

\subsection{Gender-Effect}

The patient group comprised 50 patients, 48 of the them were men and two of them were women. While the control group $(n=50), 47$ of them were men and three of them were women (Table 1).

\subsection{Smoking-Effect}

The patients $(\mathrm{n}=50)$ classified into two groups smoker $(n=19)$ and non-smokers $(n=31)$, there were no significant effect of smoking on the serum levels of the studied parameters (Table 4).

\subsection{Grade-Effect}

The comparison between different grades of $\mathrm{BC}$ was presented in (Table 5) to recognize the grade effect on the serum levels of the focused parameters. The serum levels of the studied parameters decreased according to the grade progression regarding SOD, GPX, and CAT, while, in term of XO the serum levels of XO increased according to the grade progression but these differences did not reach the significant levels.

Table 4. Comparison between smoker and non-smoker groups regarding the serum levels of the studied parameters

\begin{tabular}{|c|c|c|c|c|c|}
\hline & Smoking & $\mathbf{N}$ & Mean & \pm SD & p \\
\hline \multirow{2}{*}{$\mathrm{SOD} \mathrm{u} / \mathrm{ml}$} & Yes & 19 & 153.337 & 23.4853 & \multirow{2}{*}{0.439} \\
\hline & No & 31 & 146.568 & 32.9801 & \\
\hline \multirow{2}{*}{ GPX u/l } & Yes & 19 & 132.1105 & 13.59401 & \multirow{2}{*}{0.677} \\
\hline & No & 31 & 130.3316 & 15.15829 & \\
\hline \multirow{2}{*}{$\mathrm{XO}$ u/l } & Yes & 19 & 2.2463 & .83805 & \multirow{2}{*}{0.993} \\
\hline & No & 31 & 2.2442 & .84208 & \\
\hline \multirow{2}{*}{ CAT u/l } & Yes & 19 & 9.7353 & 2.83448 & \multirow{2}{*}{0.115} \\
\hline & No & 31 & 10.8768 & 2.17073 & \\
\hline \multirow{2}{*}{ Tumor-size } & Yes & 19 & 420.1053 & 499.87164 & \multirow{2}{*}{.444} \\
\hline & No & 31 & 336.4194 & 267.27798 & \\
\hline \multirow{2}{*}{ Age } & Yes & 19 & 65.32 & 8.340 & \multirow{2}{*}{0.599} \\
\hline & No & 31 & 66.74 & 9.764 & \\
\hline
\end{tabular}

Table 5. Comparison between different grades of bladder cancer regarding the serum levels of the studied parameters

\begin{tabular}{|c|c|c|c|c|c|c|}
\hline & Grades & $\mathbf{N}$ & Mean & \pm SD & PANOVA & Signif icance (LSD) \\
\hline \multirow{4}{*}{ Age } & I & 12.000 & 65.333 & 7.855 & \multirow{4}{*}{.669} & \multirow{4}{*}{ NA } \\
\hline & II & 20.000 & 65.300 & 7.801 & & \\
\hline & III & 18.000 & 67.778 & 11.456 & & \\
\hline & Total & 50.000 & 66.200 & 9.187 & & \\
\hline \multirow{4}{*}{$\mathrm{SOD} \mathrm{u} / \mathrm{ml}$} & I & 12.000 & 149.658 & 32.815 & \multirow{4}{*}{.881} & \multirow{4}{*}{ NA } \\
\hline & II & 20.000 & 151.300 & 27.517 & & \\
\hline & III & 18.000 & 146.394 & 31.281 & & \\
\hline & Total & 50.000 & 149.140 & 29.657 & & \\
\hline \multirow{4}{*}{ GPX u/l } & I & 12.000 & 131.390 & 14.137 & \multirow{4}{*}{.995} & \multirow{4}{*}{ NA } \\
\hline & II & 20.000 & 130.862 & 13.964 & & \\
\hline & III & 18.000 & 130.914 & 15.998 & & \\
\hline & Total & 50.000 & 131.008 & 14.468 & & \\
\hline \multirow{4}{*}{$\mathrm{XO}$ u/l } & I & 12.000 & 2.186 & 0.689 & \multirow{4}{*}{.962} & \multirow{4}{*}{ NA } \\
\hline & II & 20.000 & 2.265 & 0.818 & & \\
\hline & III & 18.000 & 2.262 & 0.968 & & \\
\hline & Total & 50.000 & 2.245 & 0.832 & & \\
\hline \multirow{4}{*}{ CAT u/l } & I & 12.000 & 10.348 & 2.045 & \multirow{4}{*}{.965} & \multirow{4}{*}{ NA } \\
\hline & II & 20.000 & 10.559 & 2.641 & & \\
\hline & III & 18.000 & 10.378 & 2.682 & & \\
\hline & Total & 50.000 & 10.443 & 2.480 & & \\
\hline \multirow{4}{*}{ Tumor-size } & I & 12.000 & 159.083 & 58.402 & \multirow{4}{*}{.010} & \multirow{2}{*}{ I X III } \\
\hline & II & 20.000 & 323.600 & 137.378 & & \\
\hline & III & 18.000 & 557.222 & 548.771 & & \multirow{2}{*}{ II X III } \\
\hline & Total & 50.000 & 368.220 & 370.419 & & \\
\hline
\end{tabular}




\subsection{Stage-Effect}

There were a differences between stage I and stage II regarding the serum levels of the studied parameters, but these differences did not reach the significant differences (Table 6).

\subsection{Tumor Size-Effect}

The tumor size is affected by age factor, there were significant differences between two age categories $<60$ and $60-69 \mathrm{p}=0.042$ ( Table 3). In addition, tumor size is not affected by smoking, there was no significant differences between smoker and non-smoker groups $\mathrm{p}=0.444$ (Table 4).

The tumor size is increased significantly according to the grade progression, there were significant differences between grade IXIII and IIXIII $p=0.01$ (Table 5). Moreover there was no significant difference in term of tumor size between stage I and II $\mathrm{p}=0.207$ (Table6).

\subsection{Correlation Coefficient}

There were no signification correlation coefficient between all studied parameters $p>0.05$ (Table 7).

Table 6. The effect of stage bladder cancer on the serum levels of the studied parameters

\begin{tabular}{|c|c|c|c|c|c|}
\hline & Stage & $\mathbf{N}$ & Mean & \pm SD & $\mathbf{p}$ \\
\hline \multirow{2}{*}{$\mathrm{SOD} \mathrm{u} / \mathrm{ml}$} & I & 28 & 150.418 & 29.7148 & \multirow{2}{*}{0.735} \\
\hline & II & 22 & 147.514 & 30.2012 & \\
\hline \multirow{2}{*}{ GPX u/1 } & I & 28 & 130.7286 & 13.10935 & \multirow{2}{*}{0.880} \\
\hline & II & 22 & 131.3627 & 16.34713 & \\
\hline \multirow{2}{*}{$\mathrm{XO}$ u/l } & I & 28 & 2.2393 & .79985 & \multirow{2}{*}{0.957} \\
\hline & II & 22 & 2.2523 & .89015 & \\
\hline \multirow{2}{*}{ CAT u/l } & I & 28 & 10.6350 & 1.92052 & \multirow{2}{*}{0.542} \\
\hline & II & 22 & 10.1986 & 3.08141 & \\
\hline \multirow{2}{*}{$\begin{array}{l}\text { Tumor- } \\
\text { size }\end{array}$} & I & 28 & 309.2143 & 430.61363 & \multirow{2}{*}{0.207} \\
\hline & II & 22 & 443.3182 & 266.83281 & \\
\hline \multirow{2}{*}{ Age } & I & 28 & 65.39 & 9.069 & \multirow{2}{*}{0.489} \\
\hline & II & 22 & 67.23 & 9.446 & \\
\hline
\end{tabular}

Table 7. Correlation coefficient between all studied parameters in patient group

\begin{tabular}{|c|c|c|c|c|c|c|c|}
\hline & & Age & SOD u/ml & GPX u/l & XO u/l & CAT u/l & Tumor-size \\
\hline \multirow{3}{*}{ Age } & Pearson Correlation & 1 & -.041 & .019 & .132 & -.008 & -.035 \\
\hline & Sig. (2-tailed) & & .776 & .894 & .360 & .957 & .809 \\
\hline & $\mathrm{N}$ & 50 & 50 & 50 & 50 & 50 & 50 \\
\hline \multirow{3}{*}{$\mathrm{SOD} \mathrm{u} / \mathrm{ml}$} & Pearson Correlation & -.041 & 1 & .168 & .110 & -.085 & -.156 \\
\hline & Sig. (2-tailed) & .776 & & .243 & .449 & .557 & .278 \\
\hline & $\mathrm{N}$ & 50 & 50 & 50 & 50 & 50 & 50 \\
\hline \multirow{3}{*}{ GPX u/l } & Pearson Correlation & .019 & .168 & 1 & -.120 & .199 & -.011 \\
\hline & Sig. (2-tailed) & .894 & .243 & & .405 & .165 & .941 \\
\hline & $\mathrm{N}$ & 50 & 50 & 50 & 50 & 50 & 50 \\
\hline \multirow{3}{*}{$\mathrm{XO}$ u/l } & Pearson Correlation & .132 & .110 & -.120 & 1 & .265 & -.117 \\
\hline & Sig. (2-tailed) & .360 & .449 & .405 & & .063 & .417 \\
\hline & $\mathrm{N}$ & 50 & 50 & 50 & 50 & 50 & 50 \\
\hline \multirow[b]{2}{*}{$\mathrm{CAT} \mathrm{u} / 1$} & Pearson Correlation & -.008 & -.085 & .199 & .265 & 1 & -.078 \\
\hline & Sig. (2-tailed) & .957 & .557 & .165 & .063 & & .592 \\
\hline \multirow{3}{*}{ Tumor-size } & Pearson Correlation & -.035 & -.156 & -.011 & -.117 & -.078 & 1 \\
\hline & Sig. (2-tailed) & .809 & .278 & .941 & .417 & .592 & \\
\hline & $\mathrm{N}$ & 50 & 50 & 50 & 50 & 50 & 50 \\
\hline
\end{tabular}

\section{Discussion}

\subsection{General View}

Epidemiological studies reveal that low levels of antioxidants are associated with an increased risk of BC. Antioxidant depletion in the circulation may be due to the scavenging of lipid peroxides as well as sequestration by tumor cells [11]. Some defense mechanisms in the body prevent the development of FRs, one of the most important antioxidant enzymes is SOD, which catalyzes the dismutation of super-oxide anion into $\mathrm{H}_{2} \mathrm{O}_{2}$, which is removed by CAT and GPX.

Oxidative stress induces a cellular redox imbalance that has been found to be present in various BC cells as compared with normal cells, the redox imbalance thus may be related to oncogenic stimulation [6].
The disturbance of the pro-oxidant / antioxidant balance, resulting from increased FR generation, antioxidant enzyme inactivation, and excessive antioxidant utilization, which is the causative effect of oxidative damage [3].

The goal of this study was to examine the association between serum anti-oxidant enzymes levels with incidence of the BC. The present study addressed, the role of antioxidant enzymes in Erbilian patients with $\mathrm{BC}$ and illustrated the clinical significance of these alterations in combination pattern .

\subsection{Effect of Bladder Cancer on the Serum Levels of the Studied Parameters}

\subsubsection{Superoxide Dismutase}

The result revealed that there was a significant reduction in the serum levels of SOD as compared with control group $\mathrm{p}<$ 
0.001 (Table 2).

The result of the current study was concordant with previous findings [22-25].

The explanation for the decreased SOD activity could be due to accumulation of highly diffusible and potent superoxide anion, which causes deleterious effects at sites far away of the tumor site [26].

\subsubsection{Glutathion Peroxidase}

The result presented that there was a significant reduction in the serum levels of GPX as compared with control group $\mathrm{p}<0.001$ (Table 2).

The result of the current study was consistent with previous findings $[23,25,27]$.

The explanation for the decline of GPX enzyme activity which has a role in enzymatic defense mechanism and antioxidation. Thus, it was suggested that BC and OS are closely related. Beside, it was reported that, GPX activity may be inactivated in OS conditions by superoxide anion and toxic ligands such as MDA could partially inhibit GPX activity [28], with the reduced GPX level, detoxification of $\mathrm{H}_{2} \mathrm{O}_{2}$ to $\mathrm{H}_{2} \mathrm{O}$ stays insufficient.

\section{(i) Catalase}

The statistical study has shown that there was a significant reduction in the serum catalase level as compared with control group $\mathrm{p}<0.001$ (Table 2) and this finding was consistent with the previous results [22,29-35].

The significantly reduced capacity of a variety of tumors for detoxifying $\mathrm{H}_{2} \mathrm{O}_{2}$ is linked to a decreased level of CAT.

In contrast, the studies of [36,37] found significantly increased CAT activity in the serum of $\mathrm{BC}$ patients.

The observed redox imbalance in $\mathrm{BC}$ as a consequence of decreased levels of antioxidant enzymes levels in circulation, may be important factors in $\mathrm{BC}$ incidence, development and progression, this concept was consistent with finding of [25].

Accordingly, the current finding suggests possible use of antioxidant supplementation as prophylactic agents for prevention and treatment or complementary therapy of BC.

\section{(ii) Xanthine Oxidase}

The statistical study has shown that there was a significant elevation in the serum level of XO as compared with control group $\mathrm{p}<0.001$ (Table 2) and this finding was in harmony with the previous results $[21,29,38,39]$.

The explanation for the significant elevation in the serum XO level that, the researchers contributed the elevation of this enzyme to an unbalancement variation in oxidantantioxidant status due to the $\mathrm{BC}$ process. In addition, [21] found that $\mathrm{XO}$ level elevated in $\mathrm{BC}$ patients suggested that OS might be higher in cancerous changes and process, and may affect the course of the disease. The XO-mediated free oxygen radical production in the cancerous tissue. On the other hand, as proposed by [29] increased XO level may be an attempt to reduce salvage pathway activity for purines, which is important for rapid DNA synthesis in BC cells.

Results suggest that levels of purine metabolizing enzymes increased with elevated purine metabolism in cancerous cells and, enzymatic antioxidant defense mechanism of cancerous tissues suppressed due to carcinogenic processes. Reduced antioxidant defense mechanism makes the cancerous cells more vulnerable to damage effects of some free-radical species. Results indicated that purine metabolism and salvage pathway activity of purine nucleotides were increased in the human BC tissue by suppressed XO levels, probably together with variation in some other related enzyme activities and, free radical metabolizing-enzyme activities were decreased in $\mathrm{BC}$ cells, which indicated the exposure of $\mathrm{BC}$ to more FR stress. On the contrary of current results, [22] who reported that, activity of $\mathrm{XO}$ was decreased in patients with $\mathrm{BC}$ as compared with control group.

The decreased of the antioxidant defense can be explained by few theories. It is possible that the circulating antioxidant enzymes might be exhausted by the process to counteract the enhanced lipid peroxidation in the tumor tissue. Another possibility is that the increased lipid peroxidation occurs as a result of the insufficient power of a depleted antioxidant defense system for a long time [40]. Reduction the activities of these antioxidant enzymes were that, however, excess ROS can overwhelm the capacity of the antioxidant system, the total antioxidant activity in the cells was not sufficient to antagonize the damage effects of free radicals [9].

Many researchers have previously shown that antioxidant systems are impaired in cancer patients [41-43]. Reactive oxygen species have multiple functions and are implicated in tumor initiation and progression $[44,45]$.

\subsection{Age-Effect}

The current study exhibited that, the mean age of the patients at diagnosis was $(65 \pm 10.23)$ (Table 1). Accordingly, this finding is agreeable with the concept that elderly individuals were considered at a high risk to get $\mathrm{BC}$ as well as consistent with the previous result of [46] who published that patient's average age was 62.6 years at diagnosis, moreover, [47] reported that BC affects mainly elderly people with a median age at diagnosis of 65-70 years.

The comparison between different age categories regarding the serum levels of focused parameters were presented in (Table 3), there were no significant differences between different age categories regarding the serum levels of focused parameters.

There were no age -effect on the serum levels of studied parameters, (Table 7) reveals that, there was a negative, non significant, weak correlation between age and SOD $r=-0.41$, $\mathrm{p}=0.776$, in addition there was positive, non significant weak correlation between age and GPX r $=0.19, \mathrm{p}=0.894$ and there was a positive, non significant weak correlation between age and $\mathrm{XO} \mathrm{r}=0.132, \mathrm{p}=0.360$, there was a negative nonsignificant correlation between age and CAT $r=-0.08, p=$ 0.95, and there was a negative weak non- significant correlation between age and tumor size $\mathrm{r}=-0.0 .35, \mathrm{p}=0.809$.

\subsection{Gender-Effect}

There were 50 newly diagnosed patients with $\mathrm{BC}$ of both 
genders (48 men and 2 women), so men were at higher risk to get $\mathrm{BC}$ as compared with women (Table1), this finding was in harmony with the study of [46] who reported that BC occurred more often in men than in women, moreover, it was published that, men are 3 to 4 times more likely to develop $\mathrm{BC}$ than women $[48,49]$. It was reported that, the CAT activity of women with $\mathrm{BC}$ are less than of a men [50].

\subsection{Smoking -Effect}

The patients group $(\mathrm{n}=50)$ was classified into two groups smoker $(n=20,40 \%)$, non- smoker groups $(n=30,60 \%)$ (Table $1)$.

The comparison between smoker and non-smoker groups was presented in (Table4) to detect the smoking effect on the serum levels of the studied parameters, there were no significant effect of smoking on the serum levels of the focused parameters.

Cigarette smoking is the most common risk factor and induced OS and involved in DNA damage as well as impaired anti oxidative defense mechanism. Accordingly, It is well established that $\mathrm{OS}$ and $\mathrm{BC}$ are closely related $[5,27]$. While, data of [50] has revealed a decrease in CAT activity of non-smoker patients as compared with normal individuals, and a higher decrease in catalase activity of smoker patients as compared to normal individuals.

The serum level of antioxidant enzymes might be involved in disease incidence progression and development and they were considered as a potential markers of prognosis in patients with $\mathrm{BC}$.

\subsection{Grade-Effect}

The comparison between different grades of $\mathrm{BC}$ were presented in (Table 5) to recognize the grade effect on the serum levels of the focused parameters. Regarding the tumor size, which is increased significantly according to the grade progression, so, there were a significant differences between (I X III; II X III), $p=0.01$. While, the serum levels of other studied parameters decreased according to the grade progression regarding SOD, GPX and CAT, while, in term of XO the serum levels of XO increased according to the grade progression but these variations did not reach the significant levels.

It was detected that, the differences were also found between enzyme activities in the bladder of different disease grades [22]. In a study of [23], it was found that GPX activity was much higher in patients with grade I BC, lower in those with grade III (both $\mathrm{P}<0.001$ ), but not significantly different for grade II than in controls. Besides, [38] reported that, XO activities were increased in patients with both papillary and multiple tumors compared to tumor-free group.

Xanthine oxidase values of patients in grade1 were higher than the patients having no tumor $\mathrm{p}<0.01$. In other study of [25] reported that ,SOD $\mathrm{P}<0.036$ and GPx $\mathrm{P}<0.026$ activities were significantly higher in the patients with Low grade tumors than high grade tumors. While, [21] reported that, $\mathrm{XO}$ values of patients in grade1 were higher than the patients having no tumor $(\mathrm{p}<0.01)$.

\subsection{Stage-Effect}

There were no significant stage effect on the serum levels of studied parameters (Table 6). It was published that, the results suggested that with advancing stage of $\mathrm{BC}$, the levels of OS increase, while levels of antioxidant molecules SOD ,GPX decrease [25]. While, [21] investigated regarding to the depth of tumors, the differences in XO values between the patients having no tumor and superficial tumor was statistically significant $p<0.037$. Differences were also found between enzyme activities in the bladder of different disease stages [22]. Enhanced angiogenesis was evident by alteration in the serum levels of antioxidant enzymes, which were associated with relatively advanced tumor stage, as they showed a significant direct correlation with the stage of BC.

\subsection{Tumor Size-Effect}

The tumor size is affected by age factor, these finding is in harmony with the concept that advanced age is considered as risk factor, so the tumor size is increased significantly with age, the result of the current study revealed that, there were significant differences between two age categories $<60$ and 60-69 $p=0.042$ ( Table 3).In addition, tumor size is not affected by smoking, there was no significant differences between smoker and non-smoker groups $p=0.444$ (Table 4 ).

The tumor size is increased significantly according to the grade progression, there were significant differences between grade IXIII and IIXIII $p=0.01$ (Table 5), this finding was concordant with concept that the tumor size is significantly affected by the grade progression.

Moreover there was no significant difference in term of tumor size between stage I and II p=0.207 (Table 6).

\subsection{Correlation Coefficient}

There were no signification correlation coefficient between all studied parameters $\mathrm{p}>0.05$ (Table 7). An interesting and novel finding in the present study was the correlation between aberrant expressions of the studied markers in combination patterns with the incidence of the BC in Erbil population.

The strength of the present work lies in the fact that this is the first attempt that includes enzymatic antioxidants parameters in BC patients in a single study and the results are correlated according with other confounding factors age, gender, smoking, grade, stage and tumor size. In the light of these findings, it can be suggested that, change in serum levels of some biochemical parameters could assist in diagnosis and follow-up of BC.

These data suggested that serum levels of these parameters might be of value in estimating the extent of tumor dissemination, assigning prognosis, and monitoring response to therapy in patients with $\mathrm{BC}$. These markers might be a potentially important as an additional biochemical diagnostic tool and an informative potential prognostic marker for BC and could be a useful tool to predict and control progression of BC. Based on these results that, these findings suggested possible involvement of OS in the pathogenesis of BC. 
Antioxidants have been favored as prophylactic agent in the treatment of patients at high risk for the development of bladder cancer and have also found to be effective in reducing therapy-related side effects. Anti-oxidant enzymes could be used as prognostic biomarkers in BC.

These data highlight the importance of these findings that, this work was believed to shade the essential biochemical markers that could be important candidates for $\mathrm{BC}$ diagnosis as a useful diagnostic tool and they provided primarily a potential etiologic insight, in addition, these findings may have future implications for the treatment of patients with metastatic disease.

\section{Conclusions}

The results of the present study revealed a significant alterations in serum antioxidant enzymes levels in BC patients as compared with the control group, indicating presence of OS in $\mathrm{BC}$ patients. These results suggest possible involvement of $\mathrm{OS}$ in the pathogenesis of $\mathrm{BC}$. In addition, there were no age, smoking, grade, stage effects on the serum levels of the studied parameters as well as there was no tumor size effect, except that there was a tumor size significant differences between different grades.

The observed redox imbalance in $\mathrm{BC}$ as a consequence of altered levels of antioxidant enzymes, may be important factors in tumor incidence, development and progression. These findings suggest possible use of antioxidant supplementation as prophylactic agents for prevention and treatment of BC. In addition, it is clear from this study that determining the levels of anti-oxidant enzymes in patients with $\mathrm{BC}$ may be a good indicator to evaluate this disease and might be a potentially important findings as an additional diagnostic biochemical tools for BC.

Further investigations in a larger cohort of patients with $\mathrm{BC}$ are needed to enlighten the possible diagnostic role of antioxidant enzymes in BC. Further Large clinical trials are now planned to confirm or refute this hypothesis. In addition, understanding the role of ROS at the molecular level is important for designing appropriate prevention strategies and development of new therapeutic approaches.

\section{Abbreviations}

Bc: Bladder cancer, CAT: catalase, GPX: glutathione peroxidase, $\mathrm{H}_{2} \mathrm{O}_{2}$ : hydrogen peroxide, OS: oxidative stress, ROS: reactive oxygen species, RNS: reactive nitrogen species, SOD: superoxide dismutase , XO: xanthine oxidase, FR: free radical.

\section{References}

[1] Yoshiyuki Kakehi1,Yoshihiko Hirao, Wun-Jae Kim, Seiichiro Ozono, Naoya Masumori,NaotoMiyanaga, Yasutomo Nasu and Akira Yokomizo, (2010). Bladder Cancer Working Group Report. Jpn. J. Clin. Oncol, 40(1): 57-64.
[2] Iraqi Cancer Registry (ICR) (2005).

[3] Aymelek Gönenç, Derya Erten , Sabahattin Aslan ,Melih Akınc1, Bolkan Şimşek and Meral Torun, (2006). Lipid peroxidation and antioxidant status in blood and tissue of malignant breast tumor and benign breast disease. Cell Biol Int,30(4): 376-380.

[4] Nishikawa M. (2008). Reactive oxygen species in tumor metastasis.Cancer Lett, 266: 53-59.

[5] Barry Halliwell, (2007). Oxidative stress and cancer: have we moved forward?. Biochem. J., $401: 1-11$.

[6] Valko M, Rhodes CJ, Moncol J, Izakovic M, Mazur M. (2006). Free radicals, metals, and antioxidants in oxidative stress - induced cancer. Chem Biol Interact, 160(1): 1-40.

[7] Kumar B, Koul S, Khandrika L, Meacham RB, Koul HK. (2008). Oxidative stress is inherent in prostate cancer cells and is required for aggressive phenotype.Cancer Res, 68(6): 17771785 .

[8] Kyeong-Ah Jung and Mi-Kyoung Kwak, (2010). The Nrf2 System as a Potential Target for the Development of Indirect Antioxidants. Molecules, 15: 7266-7291.

[9] Al-Gayyar, M.M., Eissa, L.A., Rabie, A.M., El-Gayar, A.M. (2007). Measurements of oxidative stress status and antioxidant activity in chronic leukaemia patients. J. Pharm. Pharmacol, 59: 409-417.

[10] Valko, M.; Leibfritz, D.; Moncol, J.; Cronin, M.T.; Mazur, M.; Telser, J. (2007). Free radicals and antioxidants in normal physiological functions and human disease. Int. J. Biochem. Cell. Biol, 39: 44-84.

[11] Sharma A, Rajappa M, Saxena A, Sharma M. (2007). Antioxidant status in advanced cervical cancer patients undergoing neoadjuvant chemoradiation.Br J Biomed Sci, 64(1): $23-27$.

[12] Arseniy E. (2012). Yuzhalin and Anton G. Kutikhin. Inherited variations in the SOD and GPX gene families and cancer risk. Free Radical Research, 46(5): 581-599.

[13] Oberley, L. W.(2005). Mechanism of the tumor suppressive effect of MnSOD overexpression. Biomed. Pharmacother, 59: 143-148.

[14] Elchuri, S., Oberley, T. D., Qi, W., Eisenstein, R. S., Jackson Roberts, L., Van Remmen, H., Epstein, C. J. and Huang,T.T. (2005). CuZnSOD deficiency leads to persistent and widespread oxidative damage and hepatocarcinogenesis later in life. Oncogene, 24: 367-380.

[15] Kang, S. W., Rhee, S. G., Chang, T. S., Jeong, W. and Choi, M. H. (2005). 2-Cys peroxiredoxin function in intracellular signal transduction: therapeutic implications.Trends Mol. Med, 11: 571-578.

[16] Khan MA, Tania M, Zhang D, Chen H. (2010). Antioxidant enzymes and cancer. Chin J Cancer Res, 22 (2): 87-92.

[17] Ahn J, Ambrosone CB, Kanetsky PA, Tian C, Lehman TA, Kropp S, Helmbold I, von Fournier D, Haase W, Sautter-Bihl ML, Wenz F, Chang-Claude J. (2006). Polymorphisms in genes related to oxidative Stress (CAT, MnSOD, MPO, and eNOS) and acute toxicities from radiation therapy following lumpectomy for breast cancer. Clin Cancer Res, 12: 7063 7070 . 
[18] Chelikani P, Fita I, Loewen PC. (2004). Diversity of structures and properties among catalases. Cell. Mol. Life Sci, 61(2): 192-208.

[19] McEligot A.J., Yang S., Meyskens F.L. (2005). Redox regulation by intrinsic species and extrinsic nutrients in normal and cancer cells. Ann. Rev. Nutr, 25: 261-295.

[20] Harrison R. (2002). Structure and function of xanthine oxidoreductase. where are we now? Free Radic Biol Med, 33: 774-797.

[21] Gülec M, Akin H, Yüce H, Ergin E, Elyas H, Yalcin O, Akyol O. (2003). Adenosine deaminase and xanthine oxidase activities in bladder washing fluid from patients with bladder cancer: a preliminary study. Clin Biochem, 36: 193-196.

[22] İlker Durak, Hakki Perk, Mustafa Kavutçu, Orhan Canbolat, Ömer Akyol, Yaßar Bedük, (1994). Adenosine deaminase, 5'nucleotidase, xanthineoxidase, superoxide dismutase, and catalase activities in cancerous and noncancerous human bladder tissues. Free Radical Biology and Medicine, 16(6): 825-831.

[23] YalçinO., Karataş F., Erulaş F. A., Özdemir E. (2004). The levels of glutathione peroxidase, vitamin A, E, C and lipid peroxidation in patients with transitional cell carcinoma of the bladder. BJU International, 93(6): 863-866.

[24] Zhou, F., Zhang, W.,Wei, Y., Zhou, D., Su, Z., Meng, X., Hui, L., Tian, W. (2007). The changes of oxidative stress and human 8-hydroxyguanine glycosylasel gene expression in depressive patients with acute leukemia. Leuk. Res,31: 387393.

[25] Nitika Badjatia, Abhigyan Satyam, Prabhjot Singh, Amlesh Seth and Alpana Sharma, (2010). Altered antioxidant status and lipid peroxidation in Indian patients with urothelial bladder carcinoma. Urologic Oncology. Seminars and Original Investigations, 28(4): 360-367.

[26] Aydin A, Arsova-Sarafinovska Z, Sayal A, Eken A, Erdem O, Erten K, Ozgök Y, Dimovski A.(2006). Oxidative stress and antioxidant status in non-metastatic prostate cancer and benign prostatic hyperplasia.Clin Bioche,36(2): 176-179.

[27] Arikan S, Akcay T, Konukoglu D, Obek C and Kural AR.(2005). The relationship between antioxidant enzymes and bladder cancer. Neoplasma, 52(4):314-317.

[28] Blum J. and Fridovich I. (1985). Inactivation of glutathioneperoxidase by superoxide radical. Arch Biochem Biophys, 240: 500-508.

[29] Durak, H. Perk, M. Kavutcu, O. Canbolat, O. Akyol, Y. Beduk, (1994). Adenosine deaminase, 5'-nucleotidase, xanthineoxidase, superoxide dismutase, and catalase activities in cancerous and noncancerous human bladder tissues. Free Radic. Biol. Med, 16: 825-831.

[30] Singh S.V., Xu B.H., Tkalcevic G.T., Gupta V., Roberts B., Ruiz P. (1994). Glutathione-linked detoxification pathway in normal and malignant human bladder tissue .Cancer Lett, 77: $15-24$.

[31] Storz P. (2005). Reactive oxygen species in tumor progression.Front Biosci, 10 :1881-1896.

[32] Battisti, V.; Maders, L.D.; Bagatini, M.D.; Santos, K.F.; Spanevello, R.M.; Maldonado, P.A.; Brule, A.O.; Araujo Mdo,
C.; Schetinger, M.R.; Morsch, V.M. (2008). Measurement of oxidative stress and antioxidant status in acute lymphoblastic leukemia patients. Clin. Biochem, 41: 511-518.

[33] Nadine Hempel,Hanqing Ye,Bryan Abessi,Badar Mian and J. (2009). Andres Melendez. Altered redox status accompanies progression to metastatic human bladder cancer. Free Radical Biology and Medicine, 46(1): 42-50.

[34] Thanaa M. Juda , Mufeed J.Ewad, Kadum J.Alhamdani and Mohammed R.Judy, (2009). Correlation of Catalase with Trace Elements Zinc and Copper in Urinary Bladder Cancer Patients. Medical Journal of Babylon, 6(1) : 54-59.

[35] Cobanoglu U, Demir H, Duran M, Şehitogullari A, Mergan D, Demir C. (2010). Erythrocyte catalase and carbonic anhydrase activities in lung cancer. Asian Pac J Cancer Prev, 11(5): 1377-1382.

[36] Bayraktar N, Kilic S, Bayraktar MR, Aksoy N. (2010). Lipid peroxidation and antioxidant enzyme activities in cancerous bladder tissue and their relation with bacterial infection: a controlled clinical study. J Clin Lab Anal, 24 (10): 25-30.

[37] Necip Pirinççi, Ilhan Geçit, Mustafa Güneş, Mehmet Bilgehan Yüksel, Mehmet Kaba , Serhat Tanık, Halit Demir ,Mehmet Aslan, (2012). Serum adenosine deaminase, catalase and carbonic anhydrase activities in patients with bladder cancer. Clinics, 67 (12): 1443-1446.

[38] Mukaddes Güleç, Haluk Akın, H.üseyin Yüce, Ertürk Ergin, Halit Elyas, Orhan Yalçına andÖmer Akyol, (2003). Adenosine deaminase and xanthineoxidase activities in bladder washing fluid from patients with bladdercancer: a preliminary study. Clinical Biochemistry, 36(3): 193-196.

[39] Nadia S Metwally, Sanaa A Ali, Azza M Mohamed, Hussein M Khaled and Samia A Ahmed, (2011). Levels of certain tumor markers as differential factors between bilharzial and non-biharzial bladder cancer among Egyptian patients. Cancer Cell International.11: 11-8.

[40] Zaidi S.M., Al-Qirim T.M., Banu N. (2005). Effects of antioxidant vitamins on glutathione depletion and lipid peroxidation induced by restraint stress in the rat liver. Drugs R D, $6: 157-165$.

[41] Kacakci A, Aslan I, Toplan S, Oysu C, Aslan O and Aydemir B. (2009). Significance of the counteracting oxidative and antioxidative systems in the pathogenesis of laryngeal carcinoma. J Otolaryngol Head Neck Surg, 38: 172-177.

[42] Gokul S, Patil VS, Jailkhani R, Hallikeri K and Kattappagari KK. (2010). Oxidant-antioxidant status in blood and tumor tissue of oral squamous cell carcinoma patients. Oral Dis, 16: 29-33.

[43] Badjatia N., Satyam A., Singh P., Seth A. and Sharma A. (2010). Altered antioxidant status and lipid peroxidation in Indian patients with urothelial bladder carcinoma. Urol Oncol, 28: $360-367$.

[44] Nishigori C, Hattori Y and Toyokuni S. (2004). Role of reactive oxygen species in skin carcinogenesis. Antioxid Redox Signal, 6: 561-570.

[45] Kc S, Carcamo JM and Golde DW. (2006). Antioxidants prevent oxidative DNA damage and cellular transformation elicited by the over-expression of c-MYC. Mutat Res, 593: 64-79. 
[46] Jemal A, Murray T, Ward E, Samuels A, Tiwari RC, Ghafoor A, Feuer EJ, Thun MJ. (2005). Cancer statistics. CA Cancer J Clin, 55 (1) : 10-30.

[47] Kirkali Z, Chan T, Manoharan M, Algaba F, Busch C, Cheng L, Kiemeney L, Kriegmair M, Montironi R, Murphy WM, Sesterhenn IA, Tachibana M, Weider J. (2005). Bladder cancer: epidemiology, staging and grading, and diagnosis .Urology, 66 (6) : 4-34.
[48] Jemal A, Siegel R, Ward E, Hao Y, Xu J, Murray T, Thun M.J.(2008). Cancer statistics. CA Cancer J Clin, 58 (2) : 71-96.

[49] Parkin DM.(2008). The global burden of urinary bladder cancer. Scand J Urol Nephrol Suppl, 218: 12-20.

[50] Israa G. Zainal, Dr.Mhammed AL-Dori and Abdul-NasserM. Abdul, (2009). Study of some Antioxidants in plasma of patients with bladder cancer. Eng.\&Tech.Journal, 27( 4): 751758. 